\title{
Semiótica digital y comunicación política. El despegue y auge de Vox ${ }^{1}$
}

\section{Digital semiotics and political communication. The take-off and rise of Vox}

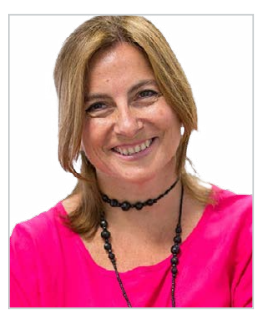

Inmaculada Berlanga Fernández. Doctora en Filología y Doctora en Comunicación Audiovisual. Actualmente es Profesora Titular en la Universidad Internacional de la Rioja. Está acreditada por ANECA en la figura de Profesor Titular de Universidad. Dos Sexenios de Investigación (CNEAI). Investigadora Principal en el grupo PROCOMM (Prospectivas en Comunicación Multimedia) de Unir Research e Investigadora Doctora en el Proyecto "Youtubers e Instagrammers: la competencia mediática en los prosumidores emergentes" (I+D: RTI2018-093303-B-I00) del Ministerio de Ciencias, Innovación y Universidades. Autora del libro Ciberretórica: Aristóteles en las redes sociales (Fragua, 2013) prologado por Darío Villanueva, secretario de la RAE; ha publicado en las revistas Computers in Human Behavior, Comunicar, El Profesional de la Información, Communication \& Society, Signa, entre otras. Visiting Professor en Università Cattolica del Sacro Cuore, Milano. Miembro del Grupo Comunicar.

Universidad Internacional de la Rioja, España

inmaculada.berlanga@unir.net

ORCID: 0000-0002-0135-624X

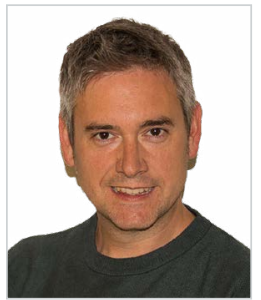

Íñigo Ortiz de Barrón Alloza. Diplomado por la Universidad del País Vasco. Graduado en Comunicación por la Universidad Internacional de la Rioja. Máster in Project Management. Ha sido docente para la formación profesional para el empleo. Investigador y profesional en Comunicación y Marketing. Durante su carrera profesional ha simultaneado diferentes proyectos en el campo de del marketing y las relaciones comerciales internacionales con los estudios de periodismo, el análisis internacional y la geopolítica. Colabora en la web Geografía Infinita en estas últimas especialidades. Universidad Internacional de la Rioja, España inigo.ortiz@unir.net

ORCID: 0000-0003-3794-2694

Recibido: 17/11/2020 - Aceptado: 11/05/2021 - En edición: 03/09/2021 - Publicado: 01/12/2021

\section{Resumen:}

Se analiza la evolución desde la invisibilidad a la sobreexposición del partido Vox (España) como fenómeno de semiosis actual, gracias a la comunicación en red. Se emplea una metodología inductiva sobre el uso de Twitter en la campaña que le consiguió este auge, y un análisis de contenido de sus mensajes desde la perspectiva semiótico-comunicacional. Los resultados muestran el audaz manejo de la red para crear un relato persuasivo en la opinión pública. Se subraya cómo los nuevos modos de comunicación digital son un campo privilegiado para el estudio de la semiótica.

\section{Palabras Clave:}

Comunicación política; Semiótica digital; Twitter; Vox.
Received: 17/11/2020 - Accepted: 11/05/2021 - Early access: 03/09/2021 - Published: 01/12/2021

\section{Abstract:}

This paper analyses the political party Vox's (Spain) evolution from invisibility to overexposure as a current semiosis phenomenon, thanks to network communication. An inductive methodology is employed regarding the use of Twitter in the campaign that saw the party's rise in popularity and a content analysis of its messages from a semioticcommunicational perspective. The results show the audacious use of the network to create a persuasive narrative in public opinion. It highlights how the new forms of digital communication are a privileged field for the study of semiotics.

\section{Keywords:}

Political communication; digital semiotics; Twitter; Vox.

1 Trabajo enmarcado en el proyecto de "Disinformation Politics Lab" (B0036-1920) financiado por la Universidad Internacional de la Rioja en el marco de la convocatoria Retos 2019.

Cómo citar este artículo:

Berlanga Fernández, I. y Ortiz de Barrón Alloza, Í. (2021). Semiótica digital y comunicación política. El despegue y auge de Vox. Doxa Comunicación, 33, pp. 53-74.

https://doi.org/10.31921/doxacom.n33a929 


\section{Introducción}

Tras años de invisibilidad en todos los medios, alejado del foco mediático y con una presencia institucional nula que puso a veces en peligro la propia existencia de la formación, el partido español Vox pasó en 2018 a convertirse en menos de seis meses en centro de la atención política del país, incrementando exponencialmente su número de simpatizantes y su presencia electoral.

Un año más tarde se convierte en la tercera fuerza política de España.

Estas circunstancias han propiciado que en estos dos años proliferen estudios y publicaciones divulgativas centradas en la comunicación en red de Vox como éxito de sus campañas; también desde la academia, trabajos de tesis (Gómez-Ciriano, 2019) y artículos científicos (Mancera Rueda \& Villar-Hernández, 2020; García-Herrero, 2019; Bernal-Triviño \& Clares-Gavilán, 2019) han abordado el análisis de las habilidades comunicativas de este partido.

En este trabajo nos proponemos como objetivo analizar el fenómeno de semiosis que supone la estrategia del partido Vox en las redes sociales, concretamente en Twitter, en el momento que puede señalarse como su despegue: la pasada campaña electoral de la Elecciones de Andalucía 2019. El estudio de la semiótica en las redes sociales es un campo apenas abordado. Ya en 2007 Warschauer y Grimes publicaron un artículo donde se analizaba la semiótica emergente de la Web 2.0 enfocándose en la audiencia, la autoría y los dispositivos. Más reciente es el artículo de Marino (2015) quien emplea un enfoque semiótico de los memes de Internet. Chauhan, Sutaria y Doshi (2018) estudian el impacto de la semiótica en el análisis de sentimientos en Twitter.

Defendemos que las tecnologías digitales, con facilidades para desarrollar marcos conceptuales y almacenar datos multidimensionales en diferentes niveles de descripción, muestran nuevas formas de conducir la investigación semiótica. La presencia de la imagen connotada subrayando el texto, el alto contenido metafórico y el hábil manejo de la pragmática en sus mensajes, despierta el interés por analizar el discurso en red de Vox desde una perspectiva semiótico-comunicacional para profundizar en los códigos comunicativos, su contexto cultural y su simbología. Estos parámetros repercuten en conductas de consumo de la red y es una forma de avanzar en la investigación semiótica del entorno digital. Con este propósito enmarcaremos el caso de estudio en el actual contexto global; y también haremos algunos apuntes sobre el papel de las nuevas tecnologías y concretamente de la red Twitter en la comunicación política, red que ha facilitado al partido Vox su trayectoria desde la invisibilidad a la sobreexposición.

\subsection{El contexto global}

En este comienzo del siglo XXI estamos siendo testigos de grandes cambios económicos, políticos, sociales y tecnológicos. De un lado, una recesión económica originada por una gran crisis financiera ha deteriorado la percepción de la democracia y hegemonía de Occidente, sacudiendo sus cimientos institucionales. Más allá de las terribles consecuencias económicas y sociales, que se traducen en desempleo, inseguridad económica y descontento, la crisis ha cambiado el equilibrio político global y ha originado una quiebra de la cohesión social que se ha materializado en el creciente desapego hacia las instituciones políticas (Fernández-Albertos, 2018). 
La estabilidad del sistema de partidos y el binomio izquierda-derecha dominante desde el fin de la Segunda Guerra Mundial se ha visto afectado. Y en este sentido, nuevos movimientos han ido surgiendo en diferentes partes del mundo con la firme intención de defender los derechos de quienes han sido los más afectados por toda esta crisis global. Asimismo, el debate sobre el encaje de los sectores más afectados por la crisis (inmigrantes, minorías, mujeres, parados, pensionistas...) ha entrado en la agenda política de todos los países. A todo ello hay que sumar la revolución digital y al auge de las nuevas tecnologías que facilitan la comunicación y una mayor exposición de la información a la vez que permiten la interconexión a nivel global. La evolución de Internet y el auge de las redes sociales han introducido silenciosa e imparablemente un cambio en el paradigma cultural tradicional.

\subsection{Las nuevas tecnologías en la comunicación política. El caso de Twitter}

Los medios de comunicación tradicionales han sido en la esfera política los instrumentos más habituales para la relación entre el emisor del mensaje (el partido o el candidato) y el sujeto receptor (la masa de votantes). Ni sus funcionalidades ni su estructura permiten una discusión activa de los asuntos públicos; además, muchas veces, no gozan de confianza por parte de los ciudadanos que se ven como meros trasmisores de unos intereses políticos concretos. La revolución digital y el desarrollo de las TIC han posibilitado un nuevo modelo de relación en la comunicación política, volviéndola bidireccional, interactiva, libre y sin limitaciones de acceso previo. Es la llamada ciberpolítica, que genera unas dinámicas de participación, control y oposición hasta ahora impensables (Cotarelo, 2013).

Las redes sociales han ido adquiriendo un peso cada vez más definitivo en las campañas electorales frente a otros medios de comunicación tradicional (Congosto, Fernández \& Moro Egido, 2011; Gómez-Calderón, Roses \& Paniagua, 2017) y ya son un canal imprescindible en las estrategias comunicativas de los actores políticos (López-Meri, Marcos-García y Casero-Ripollés, 2017). En concreto Twitter se ha ido incorporando como un medio indispensable para comunicar ideas, pero también como medio que facilita la conversación (Moya \& Herrera, 2015). En las campañas electorales una hábil estrategia comunicativa ayudada por este tipo de plataformas ha conseguido en los últimos años que partidos o líderes que se encontraban fuera del mainstream político se posicionen en la primera línea informativa. Una de las formas para lograr el máximo espacio posible en la opinión pública y polarizarla es provocar a los detractores de sus ideas para que se movilicen, hecho que, a su vez, activa a los que son fieles a la ideología del partido, que siguen esta estrategia y hacen que se propague aún más el mensaje. Cuanto más impacte un mensaje lanzado, más viral se hará y más fácil será que todo el mundo hable de él. Estar en boca de todos es el objetivo de esta estrategia (García-Beaudoux \& D’Adamo, 2013).

\subsection{La creación de un relato: el clivaje y el storytelling como recurso de la semiótica digital}

Puesto que vamos a analizar la creación de un relato político divulgado por las redes sociales parece oportuno realizar unos apuntes sobre la teoría del clivaje y el recurso al storytelling. Clivaje, en ciencia política y sociología, se refiere a la división de los votantes en diferentes bloques separados por "escisiones" o "clivajes" (del inglés cleavage). Esos puntos de fractura, de origen histórico, se han establecido en la política, y sirven en parte para analizar las tendencias de voto. Completan la teoría de Maurice Duverger (2002) sobre el origen y desarrollo de los partidos políticos y su relación con el momento histórico de la universalización del sufragio electoral. Los principales clivajes son cuatro según el modelo clásico de Lipset y Rokkan 
(2001): Propietario-Trabajador, Iglesia-Estado; Ciudad-Campo y Centro-Periferia. El clivaje político actual presente en comicios recientes en Europa y América también ha llegado a España y formaciones como Vox han sabido manejar con fuerza estas dicotomías.

El origen de esta teoría a partir de acontecimientos históricos y el hecho de que sea utilizada en la comunicación política hace que sea fácil unirla a la estrategia comunicativa del storytelling "la maquina de fabricar historias y formatear las mentes" (Salmon, 2008: 5). La necesidad del ser humano de contar historias es aprovechada por el marketing como una nueva forma de acercarse al consumidor: a través de relatos revestidos de factores emocionales se facilita el recuerdo y la identificación del publico con el sujeto transmisor de un contenido. La comunicación política también la emplea como modo de comunicación que actualiza las estrategias de persuasión y propaganda y hace del relato una oportunidad (Gutiérrez-Rubí, 2008) creando el clima emocional que favorece la recepción de los mensajes.

Como apuntan Berlanga y Sánchez (2018), con esta técnica no se trata solo de informar eficazmente a la ciudadanía; además se crea un nuevo universo virtual donde se introducen metáforas coherentes con el mensaje ideológico de la formación política. Se propone, no solo una argumentación y un programa, sino unos personajes, unos relatos y una puesta en escena de la democracia en lugar de su ejercicio. "Y el candidato ganador es aquel cuyas historias están en conexión con el mayor número de electores" (Salmon, 2008:153-154).

Umberto Eco define a la semiótica como el "estudio de todos los procesos culturales -es decir, aquellos en los que entran en juego agentes humanos que se ponen en contacto sirviéndose de convenciones sociales- como proceso de comunicación" (Eco, 2000: 53). En este sentido se comprende cómo la semiótica facilita la representación y comprensión de este relato. Enmarca el mensaje ideológico del partido, le otorga coherencia y, consecuentemente, lo acerca al ciudadano-espectador.

\subsection{Objetivos de la investigación}

Consideramos que la cultura digital, híbrida y líquida, desdibuja las divisiones tradicionales entre las disciplinas y sus referentes. El avance de la web social y semántica obliga a repensar la comunicación y la cultura; también otras ciencias tradicionales, como la sintaxis, la pragmática, la retórica y, siguiendo a Vidales (2019) la semiótica. Con todo, semiótica y retórica han sabido crear una base sólida y a la vez flexible que nos permite su aplicación para un análisis que se adapta sin sobresaltos al devenir del tiempo y de la tecnología.

A la luz de esta premisa el objetivo general de este estudio es mostrar que la evolución desde la invisibilidad a la sobreexposición del partido Vox (España) es un fenómeno de semiosis actual en el marco de la comunicación en red.

Como objetivos específicos nos proponemos: 1) Demostrar que el inesperado auge del partido Vox se debe a un buen manejo de las redes en una coyuntura sociopolítica propicia. 2) Analizar el empleo que Vox y sus líderes hacen de Twitter como herramienta estratégica de comunicación política durante las Elecciones de Andalucía 2019, y 3) Explicar el relato resultante de la campaña política de Vox sirviéndonos de la teoría semiótica. 


\section{Metodología}

Tras una búsqueda documental previa que nos ha permitido un conocimiento preliminar del objeto de estudio y plantear la investigación se realiza un análisis cuantitativo y cualitativo del discurso de Vox en la red Twitter durante el periodo de estudio. Describimos a continuación el objeto de estudio en su contexto, la muestra seleccionada y la metodología y herramientas elegidas.

\subsection{Objeto de estudio: el partido Vox en el contexto de la investigación}

Vox es un partido político español fundado a finales de 2013. Su presidente es Santiago Abascal y su secretario general es Javier Ortega Smith. Este partido es calificado de extrema derecha por algunos medios y analistas; otros lo sitúan en general en el espectro político de la derecha, pero se le define específicamente como populista, radical, reaccionario y ultraconservador (Pinto-Da Fonseca \& Pineda-Nebot, 2020). Vox no recibe ningún tipo de subvención pública y se financia con la cuota de sus afiliados y las donaciones de pequeños empresarios y profesionales. Según su propia web su proyecto se resume en la defensa de España, de la familia y de la vida; en reducir el tamaño del Estado, garantizar la igualdad entre los españoles y expulsar al Gobierno de la vida privada. Santiago Abascal se presentó por primera vez como candidato a la Presidencia del Gobierno en junio de 2016. Con una campaña basada en mítines a pie de calle y escasos simpatizantes, sus resultados fueron exiguos, un $0,2 \%$ de los votos (46.638). Fue a partir de 2016 cuando Vox asumió el poder de las redes sociales y que éstas podían ser una magnífica forma de llegar al ciudadano. Con acciones sonadas como las que recoge el artículo "La nueva hazaña de Vox: reconquistar Gibraltar con la bandera" (2016) o el protagonismo en la acusación popular en el juicio del procés catalán, fue adquiriendo relevancia en las redes sociales, cierta visibilidad en los medios digitales y se abrió camino en los medios tradicionales. Vox se convirtió en diciembre de 2018 en el partido triunfador de las elecciones al Parlamento andaluz al lograr por primera vez representación en un legislativo y batir todas las encuestas y los pronósticos que apuntaban su llegada a las instituciones, pero lejos del resultado obtenido. En 2019 obtiene 52 diputados nacionales convirtiéndose en la tercera fuerza política de España.

Bien se puede describir su trayectoria como un recorrido que va en poco tiempo de la invisibilidad a la sobreexposición. Y es que el crecimiento de afiliados ha sido exponencial. De los 5.085 con los que empezó el año 2018, se pasó a cerrar el año con 23.843 afiliados. La cifra de ciudadanos que pagaron su cuota en enero de 2020 fue 56.786 . Al mismo tiempo que el número de afiliados, también el número de simpatizantes en las redes sociales ha tenido un crecimiento continuo hasta sobrepasar las 100.000 personas. No es fácil marcar una fecha exacta a partir de la cual los medios de comunicación tradicionales comenzaron a fijarse en ese auge y a enfocar su atención en Vox. Tal vez se pueda establecer el inicio de la actividad mediática en torno a Vox a partir de su mitin de Vistalegre (Madrid) del 8 de octubre de 2018. En ese momento Vox no tenía Andalucía como objetivo; toda su estrategia estaba orientada a ir construyendo una campaña con la mirada puesta en los comicios del mes de mayo de 2019. La llamada a unas elecciones anticipadas a la Junta de Andalucía precipitó los hechos y puso a Vox en primera línea mediática. 


\subsection{Muestra}

La muestra está conformada por los tuits publicados en las cuentas de Vox y de sus principales líderes y, a modo comparativo, también del resto de partidos y candidatos de las pasadas elecciones andaluzas. La variable temporal corresponde a los días en los que se desarrolló la campaña electoral, esto es, el período del 16 al 30 de noviembre de 2018. En el caso de Vox, además de los tuits de su candidato oficial, Francisco Serrano, analizaremos los mensajes de Santiago Abascal y de Javier Ortega Smith, al considerar su representatividad dentro del partido y el hecho de que su actividad durante el periodo analizado estuvo muy enfocada a las elecciones andaluzas. Hay que señalar también que Vox carecía en ese momento de un perfil específico para Andalucía que sí tenían el resto de los partidos. Esa especificad será tenida en cuenta a la hora de valorar los resultados.

Tabla 1. Cuentas analizadas

\begin{tabular}{|c|c|}
\hline Partidos & Candidatos/Lideres \\
\hline & @Santi_ABASCAL \\
\hline @vox_es & @Ortega_Smith \\
\hline @psoedeandalucia & @FSerranoCastro \\
\hline @ppandaluz & @susanadiaz \\
\hline @Cs_Andalucia & @JuanMa_Moreno \\
\hline @AdelanteAND & @JuanMarin_Cs \\
\hline & @TeresaRodr_ \\
\hline
\end{tabular}

\subsection{Técnicas metodológicas y herramientas}

\subsubsection{Análisis cuantitativo.}

El análisis cuantitativo se detiene en dos aspectos: el uso que se hace de Twitter y la temática de los mensajes. En primer lugar, se realiza un análisis métrico sobre el uso que Vox, sus líderes y también sus principales rivales hicieron de esta red durante la campaña andaluza. Nos hemos servido de la herramienta Metricool (https://metricool.com/es/), software libre que permite analizar, gestionar y medir contenidos digitales.

En segundo lugar, se clasifican los diferentes temas mencionados en los tuits de Vox y sus líderes, con el modelo que propone el Grupo de Análisis de la Agenda Política, proyecto que recopila y organiza datos de fuentes archivadas para rastrear los resultados de las políticas en todos los países (https://www.comparativeagendas.net/). Esta clasificación plantea dieciocho variables mediáticas identificadas en la agenda política española de los últimos años. En la tabla 2 se expone el protocolo de análisis de contenido que se ha utilizado. 
Tabla 2. Clasificación de temas

\begin{tabular}{|l|l|l|}
\hline Macroeconomía & Libertades civiles & Política fiscal \\
\hline Discriminación de género & Inmigración & Política de empleo \\
\hline Medioambiente & Política social & Política de vivienda \\
\hline Política bancaria & Mercado de valores & Medios de comunicación \\
\hline Corrupción & Organización institucional & Sistema electoral y de partidos \\
\hline Gobierno y democracia & Memoria histórica & Monarquía \\
\hline Otros & & \\
\hline
\end{tabular}

Fuente: Grupo de Análisis de la Agenda Política en España

\subsubsection{Análisis cualitativo}

Una vez que se han extraído los tuits y se ha considerado la presencia de temas, palabras y conceptos, se clasifican y relacionan convenientemente mediante un análisis cualitativo para encuadrar el discurso político de estos perfiles y analizarlo desde una perspectiva semiótica.

Figura 1. Cuadro de Greimas

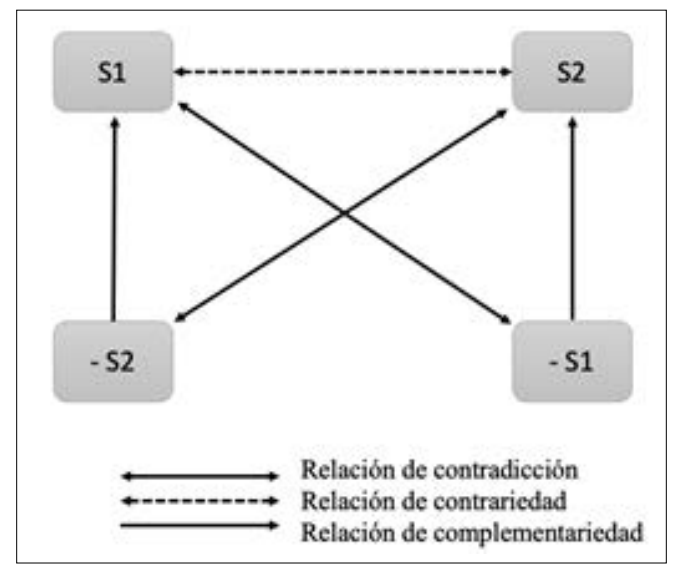

Fuente: elaboración propia

Para el análisis semiótico tomamos de referencia el modelo actancial de Greimas y lo aplicamos al discurso de Vox. El modelo actancial fue propuesto por este semiótico como referencia abreviada a los roles de Vladimir Propp (1987) en su análisis del cuento ruso, y pueden ser útiles para analizar cualquier historia o relato, sea real o ficcional. El modelo se estructura con la simplificación de los roles que los personajes de un relato asumen en el desarrollo de la historia (Greimas y Courtés, 1979). Así, 
encontramos a un Sujeto que desea un Objeto, esto es, un valor: por ejemplo, ser amado, felicidad o poder. Es ayudado por un Ayudante y confrontado negativamente por un Oponente. El Destinador es una fuerza que orienta y motiva en beneficio de un Destinatario. Estos dos últimos roles normalmente adquieren un carácter social o moral. Los roles no son fijos, pueden ser dinámicos. El Sujeto es el personaje principal del esquema, pero cualquier otro personaje del relato puede pasar a sujeto y ser analizado con el modelo. Este esquema favorece el interés por la narración. Según los valores y las aspiraciones se perfilan los personajes protagonistas y antagonistas. Los roles claves de esta modelo se recogen en el llamado cuadro o cuadrado semiótico (Greimas y Courtés, 1979: 96-99), representación gráfica de la articulación lógica de una categoría semántica cualquiera, establecida sobre una oposición entre dos términos y una tipología de relaciones. Este instrumento analítico guiará nuestro análisis semiótico-comunicacional del discurso de Vox.

Para la triangulación de metodologías nos servimos del programa de análisis cualitativo MAXQDA 2020. Se asignan códigos correspondientes con los Sujetos del cuadro semiótico de Greimas y se relacionan con el discurso de los tuits. Los resultados se examinan, se comentan y se fundamentan con referencias a tuits concretos y con bibliografía al respecto. Con este análisis semiótico-comunicacional se puede dibujar el relato presentado por Vox en su campaña electoral.

\section{Análisis y resultados}

\subsection{La agenda temática planteada por Vox y sus líderes}

El análisis de los tuits con la herramienta Metricool nos permite recuperar la frecuencia y los ejes temáticos planteados en la campaña de Vox y sus líderes.

Tabla 3. Datos métricos de los candidatos

\begin{tabular}{|l|l|l|l|l|l|l|l|}
\hline Candidato & $\begin{array}{l}\text { Santiago } \\
\text { Abascal }\end{array}$ & $\begin{array}{l}\text { Francisco } \\
\text { Serrano }\end{array}$ & $\begin{array}{l}\text { Javier O. } \\
\text { Smith }\end{array}$ & $\begin{array}{l}\text { Susana } \\
\text { Díaz }\end{array}$ & $\begin{array}{l}\text { Juanma } \\
\text { Moreno }\end{array}$ & Juan Marín & $\begin{array}{l}\text { Teresa } \\
\text { Rodríguez }\end{array}$ \\
\hline Antigüedad de la cuenta (años) & 8 & 6 & 6 & 6 & 8 & 7 & 7 \\
\hline $\begin{array}{l}\text { Frecuencia de tuits (media/ } \\
\text { día) }\end{array}$ & 8,49 & 3,52 & 11,32 & 0,91 & 3,2 & 4,18 & 7,62 \\
\hline No seguidores (a marzo 2019) & 193.342 & 29.421 & 53.552 & 174.757 & 65.054 & 19.710 & 312.768 \\
\hline Interacciones durante la campaña: & 88 & & & & & \\
\hline Tuits & $183 \mathrm{~K}$ & $30 \mathrm{~K}$ & $23 \mathrm{~K}$ & $24 \mathrm{~K}$ & $29 \mathrm{~K}$ & $20 \mathrm{~K}$ & $87 \mathrm{~K}$ \\
\hline Me gusta & $92 \mathrm{~K}$ & $16 \mathrm{~K}$ & $11 \mathrm{~K}$ & $15 \mathrm{~K}$ & $22 \mathrm{~K}$ & $13 \mathrm{~K}$ & $52 \mathrm{~K}$ \\
\hline Retuits & 84 & 55 & 73 & 199 & 62 & 155 \\
\hline
\end{tabular}

Fuente: Metricool (a marzo 2019)

Como puede apreciarse en la tabla 1, entre los políticos de Vox destaca Santiago Abascal en antigüedad en la red y, con bastante diferencia, en número de seguidores. Solo es superado por la edil de Unidas Podemos, con igual número de años de 
antigüedad pero que duplica los seguidores. Con todo, llama la atención el dato de 183K me gusta que recibe Abascal frente a los 87 de Teresa Rodríguez.

El análisis temático de los tuits de Vox con la herramienta que ofrece el Proyecto de agendas comparativas demuestra que las materias planteadas coinciden con los ejes centrales de su política. La agenda temática de los tres líderes de Vox es muy parecida a nivel general, pero cada uno de ellos concede mayor o menor relevancia a determinadas cuestiones. Así, por ejemplo, Santiago Abascal es quien más habla de inmigración ilegal, relacionándola en muchos tuits con el islam. La inmigración también es relacionada con el comercio ilegal y con el “top manta”. En este apartado es Javier Ortega quien más incide en ello. El único tema internacional tratado es la mención al estatus de Gibraltar. Esta cuestión es aprovechada doblemente: por un lado, como guiño electoralista a los habitantes de los municipios cercanos al Peñón y por otro como llamada de atención al patriotismo nacional que reclama su soberanía. Javier Ortega Smith es quien más apelaciones sobre ello realiza, aprovechando también el tirón mediático de sus acciones en el pasado. Es también el que más apela a las Fuerzas de Seguridad del Estado y a la equiparación salarial de todas ellas. Por otra parte, Francisco Serrano es quien más veces menciona la discriminación de género (ideología de género en su discurso). Al igual que en el caso de Javier Ortega, el candidato de Vox a la Junta fue conocido antes de engrosar la formación por sus críticas a las políticas de igualdad de género. También es el candidato de Vox el único que alude a la memoria histórica.

Común a todos los perfiles son las críticas a los medios de comunicación y la corrupción en la Junta de Andalucía. La política de empleo y la política fiscal son mencionadas, no así la política de vivienda. En relación con el medio ambiente sólo se han señalado tres subtemas: la caza, los toros y el plan hidrológico nacional; no se han encontrado referencias a otros temas medioambientales. No existe ninguna referencia ni al mercado de valores, ni a la política bancaria ni a la macroeconomía en general. Por último, solo Santiago Abascal hace una referencia a la monarquía, y a diferencia de otros perfiles de Twitter, ninguno de los analizados publica tuits de carácter más personal o de temas más amables, no relacionados con la política. 
Semiótica digital y comunicación política. El despegue y auge de Vox

Tabla 4. Análisis temático en los tuits seleccionados

\begin{tabular}{|c|c|c|c|c|}
\hline Temática & Santiago Abascal & Francisco Serrano & Javier O. Smith & vox \\
\hline \multicolumn{5}{|l|}{ Macroeconomía } \\
\hline Discriminación de género & 1 & 9 & & 6 \\
\hline Medioambiente & 3 & 6 & 1 & 8 \\
\hline \multicolumn{5}{|l|}{ Política bancaria } \\
\hline Corrupción & 5 & 4 & 2 & 15 \\
\hline Gobierno y democracia & 11 & 6 & 6 & 12 \\
\hline Libertades civiles & 1 & 4 & 5 & 9 \\
\hline Inmigración & 10 & 8 & 6 & 6 \\
\hline Política social & 3 & 3 & & 3 \\
\hline \multicolumn{5}{|l|}{ Mercado de valores } \\
\hline Organización institucional & 8 & 3 & 1 & 7 \\
\hline \multicolumn{2}{|l|}{ Memoria histórica } & 3 & & 2 \\
\hline Política fiscal & 1 & 3 & 2 & 2 \\
\hline \multicolumn{2}{|l|}{ Política de empleo } & 2 & 4 & 7 \\
\hline \multicolumn{5}{|l|}{ Política de vivienda } \\
\hline Medios de comunicación & 6 & 2 & 1 & 9 \\
\hline Sistema electoral y de partidos & 12 & 11 & 5 & 16 \\
\hline Monarquía & 1 & & & \\
\hline Actividad de campaña & 25 & 20 & 21 & 30 \\
\hline Otros & 1 & & 1 & \\
\hline Tuits totales & 88 & 84 & 55 & 132 \\
\hline
\end{tabular}

Fuente: elaboración propia 


\subsection{El desarrollo de la estrategia comunicativa de Vox en Twitter}

A partir de estos datos podemos sintetizar la estrategia comunicativa que tiene este partido. El recurso a los hashtags ayuda a encuadrar el mensaje. Vox se vale de ellos para que su discurso logre mayor repercusión y alcance: se consigue así la participación de los usuarios de la red y su mensaje se viraliza.

Tabla 5. El uso de etiquetas en la estrategia comunicativa

\begin{tabular}{|l|l|l|}
\hline \multicolumn{3}{|c|}{ Hashtags más presentes } \\
\hline \#EspañaViva & \#VotaVOX & \#AndalucíaPorEspaña \\
\hline \#AndalucíaVotaVOX & \#EspañaQueMadruga & \#ComercioLegal \\
\hline \#FakeNews & \#EquiparacionYa & \#GibraltarEspañol \\
\hline \#VotoÜtil & \#GuardiaCivil & \#SánchezLargate1D \\
\hline \#NoALaImpunidad & \#VoxVotoUtil & \#EspañaViva5 \\
\hline \#CatedralDeCórdoba & \#MezquitaCatedral & \#AraSanJuan \\
\hline
\end{tabular}

Fuente: elaboración propia

Los mensajes más difundidos por Vox se relacionan con la regeneración democrática y el patriotismo. En la mayoría de los tuits y hashtags analizados hay una constante llamada a la ciudadanía. Esta llamada es la clave de identidad del partido: la apelación a las emociones y a lo que se supone que el oyente quiere escuchar.

Otro aspecto recurrente en los tuits analizados es la relación problema/causa. Así se unen y relacionan los vocablos corrupción- socialismo, inmigración-delincuencia, comunismo-chavista, izquierda-podemita, etc. La reiteración de dos palabras en una corta frase hace que el mensaje penetre más fácilmente. Por otra parte, sin recurrir propiamente al insulto se busca la confrontación directa con recursos retóricos. Apelativos como "Derechita cobarde", o el hecho de hablar del gobierno de Susana Díaz como un "sultanato", se contrapone directamente con una manera de hacer política más habitual hasta el momento en el panorama español, y esto contribuye a que el receptor se posicione. De hecho, el tuit de Santiago Abascal con más aprobaciones y más retuiteado corresponde a un enfrentamiento dialéctico entre él mismo y Susana Díaz. 
Figura 2. Captura del tuit de Abascal más retuiteado

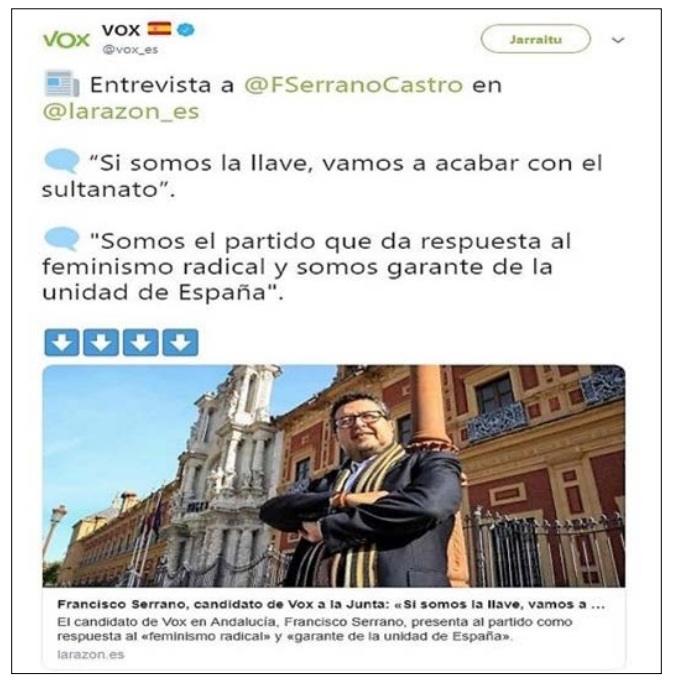

Fuente: Twitter

Es también reseñable el enfrentamiento con los medios de comunicación tradicionales, tema recurrente en su agenda mediática de campaña y etiqueta del hashtag \#FakeNews.

La ausencia de tuits de corte más personal, amables o simpáticos, denota el afán de presentarse con una imagen de seriedad, rotundidad, fuerza y preocupación o alarma ante los problemas que constantemente denuncian.

Como conclusión se puede decir que los hastags y los tuits en los que van incluidos realizan una función de encuadre y refuerzan el mensaje y el discurso de Vox donde la apelación a las emociones, el uso de símbolos, la identificación del resto de partidos con los problemas actuales y la necesidad de un cambio radical son un recurso habitual.

Figura 3. Captura de tuit sobre el final de campaña en Sevilla

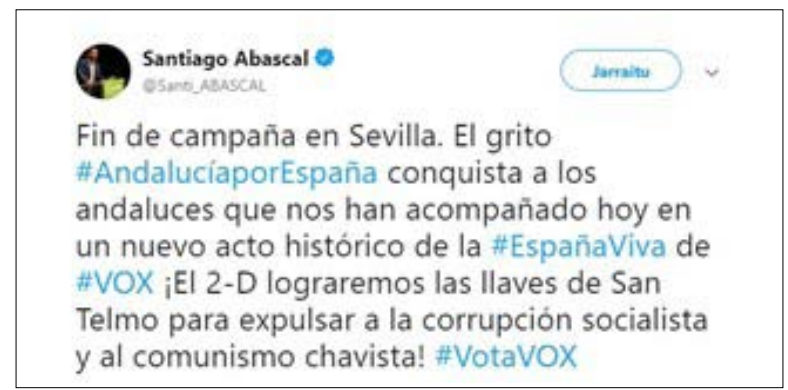

Fuente: Twitter 


\subsection{Semiótica digital en el discurso de Vox}

Como modelo aplicable a cualquier texto narrativo, en el discurso de Vox reconocemos la estructura actancial de Greimas: el Sujeto protagonista -el candidato de Vox- desea un Objeto, que en nuestro caso de estudio son los votos, que le conseguirá presencia y poder político. Cuenta como Ayudante con el hábil manejo de sus redes sociales, y como Oponente, con los medios que emplean otros partidos, especialmente de izquierdas o aquellos que pretenden neutralizarle el mensaje. La coyuntura política y social, con la crisis y la caída de valores actúa como Destinador y favorece que el mensaje llegue a su destinatario, la ciudadanía.

Figura 4. Discurso de Vox según el modelo actancial de Greimas

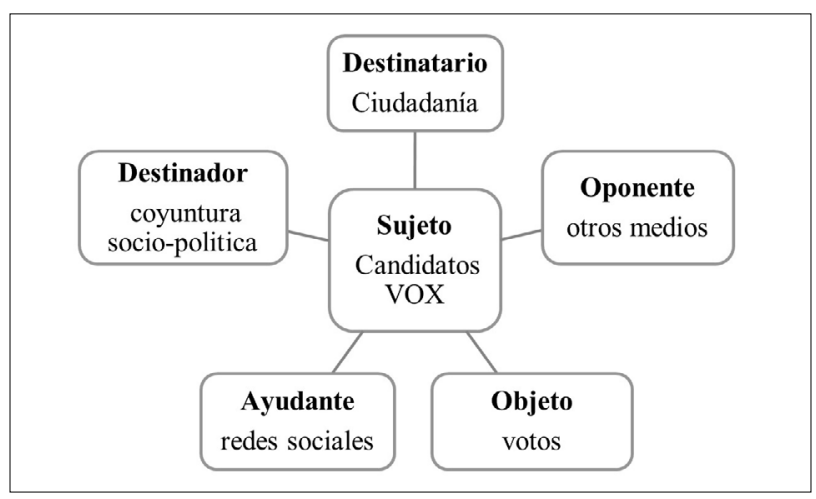

Fuente: elaboración propia

A la hora de profundizar en este análisis dejamos a un lado el objeto de deseo -los votos- puesto que sería el resultado de este relato; y también el destinatario. Es cierto que la ciudadanía, como actante prosumidor, recibe y construye un mensaje, interactúa con el sujeto protagonista y en cierto modo, puede determinar y reconducir la estrategia comunicativa. No obstante, un estudio riguroso de esta relación requeriría complementarse con otro tipo de análisis que excedería el marco de esta investigación. Por tanto, nos centramos en estos cuatro aspectos, que son los que forman el llamado cuadrado semiótico de Greimas: $\mathrm{S} 1$ = Sujeto; $-\mathrm{S} 1=$ Destinador; $\mathrm{S} 2$ = Oponente; $-\mathrm{S} 2$ = Ayudante .

\subsubsection{Sujeto actante: El factor humano del candidato}

Muy ligado al poder de la imagen, el factor humano es una de las variables de la política que mayor influencia ejerce en la ciudadanía (Guerrero \& Manzano, 2013). El esfuerzo por entablar una relación de confianza con el electorado conlleva que éste se sienta atendido por el candidato y se identifique con él.

Aunque la imagen humana de Vox es representada principalmente por su líder y presidente, Santiago Abascal, no podemos desdeñar la potencia que gran parte de sus colaboradores más cercanos reflejan: Javier Ortega Smith-Molina, abogado y ex legionario, protagonista de diversas acciones en Gibraltar; Ortega Lara, cofundador del partido, que sufrió el mayor secuestro de la historia de ETA; Ignacio Garriga, un catalán de padres guineanos; Morante de la Puebla, torero... Muchas de las reivin- 
dicaciones y del ideario político de Vox concretan la empatía que estos políticos despiertan en el electorado. Reivindicando lo políticamente incorrecto y presentándose como víctimas de la censura progresista quieren representar, por ejemplo, al trabajador español que se levanta honradamente para trabajar temprano todas las mañanas, y que, independientemente de que sea asalariado o empresario, se ve amenazado por la inmigración que viene a robarle el trabajo; o al cazador o al torero que el movimiento animalista censura; o a los hombres que por el hecho de serlo son señalados con el dedo por un presunto feminismo radical; etcétera. Las decisiones que tomarán los votantes se encontrarán siempre influenciadas por los encuadres o filtros emocionales (Entman, 1993) que relacionen el argumentario político con ese factor humano. Además, esta confluencia empática, basada en el ethos de los sujetos actantes integra, en palabras de Talens, Romera, Tordera y Hernández (1978: 47) "dentro del nivel pragmático, la relación autor/ obra y obra/lector", en este caso, emisor de los tuits y ciudadanía.

\subsubsection{Destinador: clivaje y poder retórico de la imagen}

Más allá de elementos técnicos de la imagen corporativa, los eslóganes o la simbología, nos centramos propiamente en la imagen de Vox como proyección de los valores y las creencias que el partido y sus candidatos desean promover. En el mensaje de Vox encontramos las siguientes dicotomías manejadas por el clivaje político actual:

Lo rural frente a lo urbano. La imagen del ámbito rural con sus connotaciones (religión, costumbres...) en detrimento de lo urbano (cosmopolita, progresismo...) ha sido una constante en el mensaje de Vox durante el último año y aparece reiteradamente en los tuits analizados. Es clarificador el apoyo que la formación da a la caza, a los toros y a ciertas tradiciones (tanto culturales como religiosas). Sirvan de prueba las medidas de Vox recogidas en su programa en sus números 66 y 67 que se refieren a la protección de la tauromaquia, o el número 68 sobre la Caza (Vox, 2018).

Figura 5. Captura de un tuit sobre la defensa de la caza

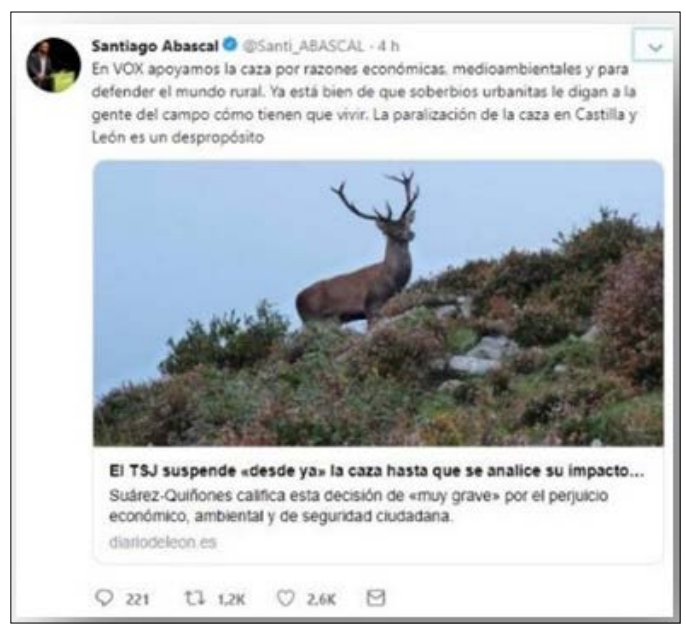

Fuente: Twitter 
Defensa de los valores y de la familia tradicional. Como parte de su ideario, la defensa de la familia y de la vida cobran especial importancia. Vox sostiene que los valores tradicionales que han mantenido cohesionado el país se encuentran en riesgo y han de salvaguardarse. En esta línea ve una seria amenaza en el movimiento feminista y el movimiento LGTBI, y los acusa de organizar un lavado de cerebro en las aulas y a través de los medios de comunicación, que consideran hegemonizados por las políticas de identidad.

Masculinidad. El sociólogo Michael Kimmel en su libro Angry White Men: American Masculinity at the End of an Era (Hombres blancos enfadados. La masculinidad de Estados Unidos en el fin de una era) habla del hecho de un posible "malestar" masculino y que afecta al comportamiento político de muchos hombres. La situación de descomposición social, política y cultural hace que caigan las certidumbres y esta coyuntura, en un contexto de un fortalecimiento del feminismo y una fractura de los valores tradicionales de la masculinidad, crea una crisis de valores muy importante (Kimmel, 2013). Vox y especialmente Santiago Abascal buscan posicionarse como defensores de los valores masculinos frente a lo que denominan ideología de género. A través de vídeos de Santiago Abascal montando a caballo, con armas, o mensajes virales con lenguaje políticamente incorrecto, se refuerza una estética masculina. Esta postura coincide con la sostenida por otros líderes mundiales (Putin, Trump...).

Épica nacionalista. Vox, como defensor de la idea de España, recurre a la Hispanidad y al período de la Reconquista como metáfora de la lucha por cambiar el establishment actual. Asimismo, la idea de defensa nacional se retroalimenta con la búsqueda de un enemigo interno (procés catalán, autonomías, el "marxismo cultural” ...) y otro externo (burocracia de la UE, inmigración, islam...).

Figura 6. Tuit de Vox con referencia a la Reconquista española

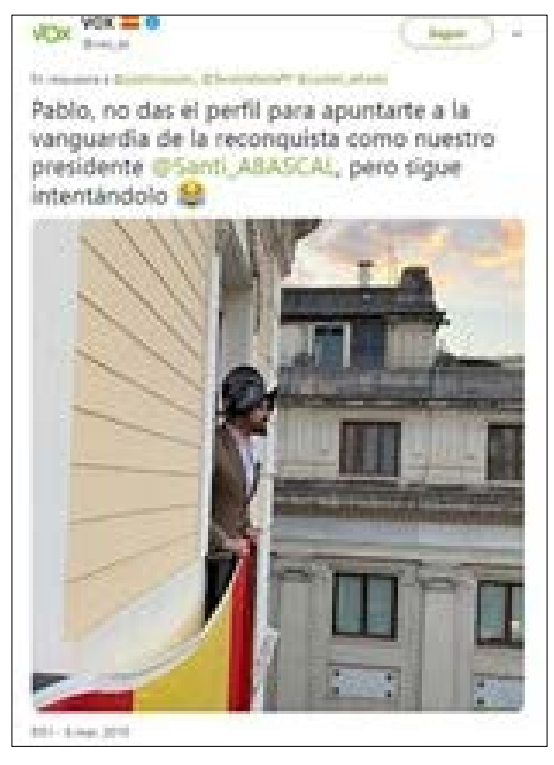

Fuente: Twitter 
Retórica bélica. "La política es la guerra". Es lo que afirmaba Santiago Abascal en la entrevista concedida para El Mundo y firmada por Leyre Iglesias en octubre de 2018. Lo militar y todo lo relacionado con ello (la marcialidad, la disciplina, el orgullo...) tiene unas claras connotaciones positivas para Vox y por eso las utiliza en su discurso. En esta retórica belicista, el adversario político se convierte en "enemigo", como también son enemigos los que se sitúan en el lado antagónico de su ideario. La exaltación de la guerra y la glorificación del más fuerte, ideas muy ligadas también a lo masculino, son acordes a otros líderes mundiales.

Corrección política. Algo que define a Vox y al resto de partidos de esta ola reaccionaria global, es la lucha contra la corrección política (Gómez, 2018), fuente de muchos de los males que afectan a la sociedad actual, según el discurso de este partido. Una imagen de malestar y de enfado se relaciona con la gravedad de la situación y la necesidad de hacerle frente. Si va acompañado con un mensaje directo, sin eufemismos, políticamente incorrecto, la fuerza de ese mensaje se acrecienta. Se añaden epítetos que la población tiende a connotarlos negativamente (bolivariano, rojo, marxista, yihaidista, feminazi...), a otras formaciones, creencias, políticas o ideas; de esta forma el mensaje se muestra contundente, y aunque pueda rozar el insulto y no le acompañe un argumento creíble, el efecto emocional se consigue. Esta estrategia podría recordar al concepto mundos posibles ficcionales de Doležel (1998), quien describe el proceso de combinación o anclaje de la historia ficcional en los sucesos históricos: el creador de un mundo ficcional tiene diversas maneras de inspirarse en el mundo real, por ejemplo, tomando prestados rasgos discursivos, culturales; es decir, hechos en bruto que transforma sutil y adecuadamente.

\subsubsection{Oponente: las campañas negativas en Vox}

Las campañas negativas son práctica común de los diferentes partidos y candidatos en períodos electorales, y tiene como fin minar al adversario, dañar su reputación o sembrar desconfianza entre el electorado (Valdez-Zepeda, 2013). En el caso de Vox tal práctica ha causado un efecto de sobredimensionamiento de su espacio, haciendo su mensaje más viral y una autoproclamación de víctima de los medios tradicionales. Al enfatizar los aspectos negativos de Vox, el resto de los partidos, medios o analistas han dado a la formación un protagonismo del que carecía hasta entonces.

Vox desde el principio ha sabido manejar hábilmente este recurso, y por ello uno de los pilares en su estrategia de comunicación ha sido la provocación y se ha valido de esta herramienta para lograr una mayor visibilidad. La provocación o la apelación directa a creencias o sentimientos arraigados lleva a una reacción visceral bien a favor o bien en contra del argumento esgrimido, que se traduce en una mayor respuesta. La propia etimología de la palabra "reaccionario" avala este hecho. Es decir, contestar, en un sentido o en otro, a un argumento, que puede parecer extremista, demagógico o simplemente falso, resulta más efectivo que un argumento más plano. Si esta reacción se produce en Twitter, Facebook u otras redes sociales, las interactuaciones se multiplican, y el algoritmo da mayor visibilidad a todas ellas. En el caso concreto de Twitter, contestar es muy provechoso para el emisor ya que así obtiene más retuits. También WhatsApp es un poderoso medio de divulgación de tuits. Hacerse viral es la capacidad de propagación de un contenido, como si de un virus contagioso se tratara, y los temas conflicticos siempre lo son. Y esto, los agentes publicitarios y los diseñadores de las campañas políticas de los diferentes partidos lo saben muy bien.

Los puntos más controvertidos expuestos durante el mitin de Vistalegre se convirtieron rápidamente en virales. Puede ser una causa de que este evento se considere su bautismo de masas. Por un lado, se provocó indignación y rechazo en sus rivales, y 
en general, agitación en toda la audiencia digital. Si 9.000 personas asistieron a Vistalegre, posteriormente, un total de 288.000 personas llegaron a expresarse a través de Twitter sobre el acto, acumulando un total de 942.000 tuits sobre Vox (Caballero, 2018). La ira y la excitación son las dos emociones que más invitan a actuar por lo que fueran comentaros negativos o positivos, un millón de personas hablaron sobre un acto de un partido sin representación durante los días posteriores. El tuit de Santiago Abascal en el que se incluye una ilustración de José María Nieto confirma elocuentemente que Vox sabe que las campañas negativas favorecen su éxito.

Figura 7. Captura de un tuit sobre referencias negativas hacia Vox

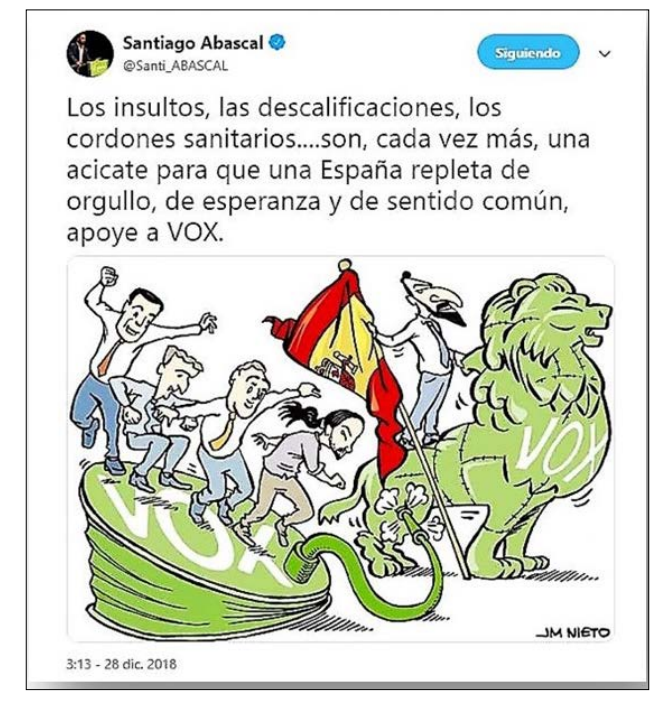

Fuente: Twitter

Tras las elecciones andaluzas que otorgó a Vox doce escaños decisivos para el cambio de Gobierno en Andalucía se lanzaron diferentes mensajes para aislar políticamente a este partido. Con todo, tanto la "alerta antifascista" lanzada por el líder de Podemos, como indica el artículo "Pablo Iglesias decreta alerta antifascista y llama a la movilización contra los postfranquistas de Vox" (2018) como la llamada al "cordón sanitario" que pidió Ciudadanos contra los de Abascal(García, 2019), así como los números actos de boicot o agresiones, provocaron un aumento en el número de afiliaciones al partido. Este crecimiento, según anunció Vox en un comunicado, permitió completar la estructura del partido en toda España con la formación de equipos en todas las provincias.

\subsubsection{La estrategia de Vox en las Redes Sociales: el Ayudante eficaz}

Sin lugar a duda, una de las claves del éxito de Vox es la eficacia en la utilización de las nuevas tecnologías y de las redes sociales en particular. Gracias a este dominio conecta con sus posibles votantes y puede transmitir su mensaje a todos los ciudadanos en general. Según datos de enero de 2019, Vox se convirtió en el partido con más seguidores en Instagram, la red social más 
seguida por los jóvenes, alcanzando la cifra de 177.000 seguidores. En YouTube se situaba en el segundo puesto, después de Podemos, con 75.278 suscriptores. Y en Facebook, con 256.560 seguidores, superaba ampliamente tanto al PP como al PSOE, los dos grandes partidos. Manuel Mariscal, Vicesecretario de Comunicación y responsable de prensa del partido es el artífice del crecimiento de Vox en las redes sociales. Este periodista, que también colaboró con el Partido Popular, es el community manager del partido y fundador del portal Politizen.

Para poder llegar al gran público, durante 2018 los discursos y mítines de Vox se comenzaron a grabar y editar para que circularan por las redes. Al mismo tiempo, potentes y polémicos memes se viralizaban a través de una telaraña de perfiles con similar ideario o gracias a voluntarios que se dedicaban a esta tarea o a la de crear hilos de discusión en diversos foros. De igual forma, se cuidaba sobremanera el contacto físico de los posibles votantes con líderes y candidatos, y se tomaban selfies o vídeos para que cada usuario pudiera compartir ese contenido con sus diferentes contactos. La táctica del contacto físico se realizó especialmente en el mundo rural por su escaso índice de penetración de redes sociales. Vox adoptó rápidamente en su agenda temas relacionados con este mundo, como la caza, la tauromaquia, etcétera.

Si se atiende a temas más prácticos, el programa electoral de Vox se encuentra con más facilidad que el de otros partidos y tiene una redacción muy clara y directa. Además, ha desarrollado una lista de difusión para poder informar directamente a todos sus simpatizantes. En palabras del propio Mariscal: “Vox reconquistó las redes sociales a la izquierda" (Müller-González, 2019). Santiago Abascal, reconocía que su partido había invertido 150.000 euros en la campaña andaluza en Internet.

Estos datos reflejan que Vox y sus líderes tienen muy interiorizado el poder de una correcta estrategia de comunicación digital y han sabido hacer de las redes sociales -Facebook, Twitter e Instragram, principalmente- y de los canales de mensajería digital -WhatsApp y Telegram- unos excelentes aliados. Hay que añadir que la actual pareja del líder de Vox es una famosa influencer, bloggera e instagramer española: Lidia Bedman (Bustamante, 2018).

\section{Discusión y conclusiones}

La globalización en este siglo XXI ha traído grandes cambios económicos, sociales y tecnológicos que por su rapidez han trastocado el paradigma global. La respuesta a esos cambios se ha polarizado en forma de guerras culturales entre izquierda y derecha, cuyos valores se han distanciado enormemente entre sí. Este fenómeno político ha crecido gracias al impulso de las nuevas tecnologías, que se han enfrentado abiertamente a los medios de comunicación tradicionales y han acentuado los debates identitarios y culturales en todas las sociedades. Y la española no es una excepción. El auge de Vox es, según se ha mostrado, una reacción múltiple a los nuevos escenarios en clave nacional: reacción al debate territorial, a la presión migratoria y, en menor medida, a los movimientos feminista o ecologista. Esta formación ha sabido detectar una demanda latente de sectores del electorado que se sienten agraviados, no representados, erigiéndose en el medio político para satisfacer dichas demandas. Junto a esta coyuntura, su hábil manejo de las redes sociales le ha hecho salir del anonimato, y dejar atrás, en menos de un año, la catalogación de partido residual y minoritario.

La semiótica tradicional, como ciencia de los signos, describe procesos de comunicación más allá del mero intercambio de mensajes. Detalla producción de significados, procesos culturales e intercambios simbólicos que la configuran como una ciencia interdisciplinar útil para analizar y comprender en mayor profundidad cualquier discurso. En esta investigación se

70 | n 33, pp. 53-74 | doxa.comunicación

julio-diciembre de 2021 
han manejado algunos conceptos y teorías de la semiótica aplicados a la comunicación política a través de las redes sociales. Aún siendo la semiótica digital y su utilización como herramienta para analizar la comunicación en red un campo emergente, consideramos que los beneficios de la sinergia semiótica-comunicación son importantes para la comprensión de nuestra sociedad y cultura. Los elementos semióticos en la comunicación de Twitter potencian su poder comunicativo y facilitan el acercamiento de la política al ciudadano medio, que a veces no cuenta con los conocimientos especializados -por ejemplo, de política o economía- necesarios para comprender un determinado mensaje. Por tanto, puede verse como un recurso didáctico que hace comprensibles los asuntos de la vida pública.

En el caso de la comunicación política, la semiosis, en forma de metáfora, consigue enmarcar el mensaje ideológico del partido o candidato, y le imprime un registro de lenguaje cercano y coherente. Su elevada carga semántica convierte el conjunto de signos en un auténtico marco o frame a través del que se hace ver el mundo y la situación política al espectador. Los mensajes contienen una multiplicidad de elementos emocionales. En ocasiones son estas emociones el hilo conductor de todo el discurso. Estos elementos emocionales facilitan el recuerdo y la identificación por parte del público y de los electores con el emisor del contenido, en este caso el partido o candidato del que se trate. La semiosis se utiliza con profusión por parte de todos los partidos políticos y en nuestro caso de los creadores de tuits, como un poderoso recurso persuasivo que reformula los esquemas comunicativos.

Volviendo al objeto de estudio, creemos haber mostrado que el partido estudiado ha utilizado estas estrategias para la difusión de su relato. De esta forma, el objetivo general de este artículo se ha conseguido: mostrar que la evolución desde la invisibilidad a la sobreexposición del partido Vox es un fenómeno de semiosis actual en el marco de la comunicación en red. De hecho, y habiéndonos centrado en las Elecciones al Parlamento de Andalucía de 2018, durante la campaña ni fueron percibidos como rivales por el resto de los oponentes políticos, ni las encuestas más generosas le auguraban tal éxito; y posteriormente su presencia mediática se ha disparado y en ocasiones sobredimensionado. Podemos concluir, pues, que la semiótica digital no solo incorpora algún concepto o teoría de la semiótica tradicional, sino que permea el acto comunicativo gracias a las nuevas tecnologías y se transforma en parte esencial de la cultura red. Este estudio sobre la comunicación política ha sido un botón de muestra.

La investigación ha contado con la limitación que otorga un objeto de estudio y un diseño metodológico recientes, con pocos años de andadura y escasa literatura al respecto. También cabe señalar que el hecho de analizar contenido político en medios de comunicación, aunque siga una metodología académica, siempre corre el peligro de dejarse influenciar por la realidad mediática diaria. Para finalizar, nos surge una pregunta: ¿Es este modelo de crecimiento del partido Vox extrapolable a otra formación en un contexto sociopolítico similar? Sin duda sería interesante abordar futuras investigaciones que recojan la estrategia comunicativa de nuevas formaciones políticas en contextos similares y realizar estudios comparativos. Dejamos abierta esta línea de trabajo.

\section{Agradecimientos}

Este artículo ha sido traducido al inglés por Sophie Phillips. 


\section{Referencias bibliográficas}

Abellán, M. \& Pardo, G. (2020). La cuestión rural en los programas de los partidos políticos en las elecciones de 2019. Tendencias Sociales. Revista de Sociología, (5), 5-34. doi.org/10.5944/ts.5.2020.27745

Berlanga I., \& Sánchez-Esparza, M. (2018). Spots políticos y retórica clásica. La metáfora y el storytelling como recurso persuasivo. VI Congreso Internacional de la AE-IC. Comunicación y Conocimiento, pp. 2190-2205. Disponible en https://bit. ly/30pqrF8

Bernal-Triviño, A. \& Clares-Gavilán, J. (2019). Uso del móvil y las redes sociales como canales de verificación de fake news. El caso de Maldita. es. El profesional de la información (EPI), 28(3). https://doi.org/10.3145/epi.2019.may.12

Bustamante, E. (3 diciembre, 2018). Lidia Bedman, la mujer que celebra junto a Santiago Abascal el éxito de Vox. El Español. Disponible en bit.ly/3e60NNE

Caballero, N. (11 octubre 2018). Las redes impulsan a VOX: casi un millón de tuits durante el mitin. El Plural. Disponible en bit.ly/3cj3l8L

Chauhan, D., Sutaria, K. \& Doshi, R. (2018, February). Impact of semiotics on multidimensional sentiment analysis on twitter: A survey. In 2018 Second International Conference on Computing Methodologies and Communication (ICCMC) (pp. 671674). IEEE. doi: 10.1109 / ICCMC.2018.8487851

Congosto, M.L., Fernández, M. \& Moro-Egido, E. (2011). Twitter y política: información, opinión y ¿predicción? Cuadernos de comunicación Evoca. 4, 11-16. Disponible en bit.ly/38azD4i

Cotarelo, R. (2013). Ciberpolítica: las nuevas formas de acción y comunicación políticas. Barcedlona: Tirant Humanidades.

Doležel, L. (1998). Heterocosmica: Fiction and Possible Worlds. London: The Johns Hopkins University Press.

Duverger, M. (2002). Los partidos políticos. FCE de España.

Eco, U. (2000). Tratado de semiótica general. Barcelona: Lumen.

Entman, R. (1993). Framing: Toward Clarification of a Fractured Paradigm. Journal of Communication, 43, 4. pp. 51-58. https:// doi.org/10.1111/j.1460-2466.1993.tb01304.x

Estos son los 19 objetivos que propone Vox para apoyar un gobierno en Andalucía. (2019, enero 8). Disponible en bit.ly/3clgvqJ Fernández-Albertos, J. (2018). Antisistema: Desigualdad económica y precariado político. Catarata.

García, L. (2019, enero 10). Abascal afea a Cs el cordón sanitario a Vox “mientras se hace fotos con Puigdemont”. La Vanguardia. Disponible en bit.ly/3clgvqJ

Garcia-Beaudoux, V. \& D’Adamo, O. (2013). Propuesta De Una Matriz De Codificación Para El Análisis De Las Campañas Negativas (Proposal of a Codification Matrix for the Analysis of Negative Campaigns). Opera, 13. Disponible en bit.ly/3bgtd5x García Herrero, F. J. (2019). La nueva política como anunciantes en la Derecha Española: VOX y las elecciones de 2018 y 2019. Redmarka. Revista de Marketing Aplicado, 23(3), 65-82. https://doi.org/10.17979/redma.2019.23.3.5867 
Gómez, D. (14 diciembre 2018). Santiago Abascal: Nos hemos rebelado contra la dictadura de la corrección política. La Verdad. Disponible en bit.ly/2NUyHKF

Gómez-Ciriano, R. (2019). El caso Vox: análisis de la comunicación de la campaña a las elecciones nacionales. [tesis doctoral]. Universidad de Valladolid. Disponible en bit.ly/38ufjLF

Gómez-Calderón, B., Roses-Campos, S. \& Paniagua-Rojano, F.J. (2017). La campaña en 140 caracteres. Empleo de Twitter por parte de los candidatos de los partidos mayoritarios ante las elecciones generales de 2016 en España. El profesional de la información, v.26, 5 (Ejemplar dedicado a: Comunicación política II), págs.816-823. https://doi.org/10.3145/epi.2017.sep.04

Greimas, A. J. \& Courtes, J. (1979). Diccionario de semiótica. São Paulo: Cultrix.

Guerrero, J. \& Manzano, M.A. (2013). El factor humano. Beok®: Un modelo para desarrollar el talento político individual. Más poder local, 17. pp 38-40. Disponible en bit.ly/3qiwmGt

Gutiérrez-Rubi, A. (2008). La política del relato. FRC: revista de debat polític, 15, 68-73. Disponible en bit.ly/38jDfRH

Kimmel, M. (2013). Angry white men: American masculinity at the end of an era. New York: Nation Books.

La nueva hazaña de Vox (2021, junio16). Disponible en bit.ly/3ccN2dm

Lipset, S. M. \& Rokkan, S. (2001). Estructuras de división, sistemas de partidos y alineamientos electorales, en Batlle, A. (ed). Diez textos básicos de ciencia política. Barcelona: Ariel.

López-Meri, A., Marcos-García, S. \& Casero-Ripollés, A-(2017). What do politicians do on Twitter? Functions and communication strategies in the Spanish electoral campaign of 2016. El profesional de la información, vol. 26, n5, pp. 795-804. https:// doi.org/10.3145/epi.2017.sep.02

Mancera-Rueda, A. \& Villar-Hernández, P. (2020). Análisis de las estrategias de encuadre discursivo en la cobertura electoral sobre Vox en los titulares de la prensa española. Doxa Comunicación, 31, pp. 315-340. https://doi.org/10.31921/doxacom. n31a16

Marino, G. (2015). Semiotics of spreadability: A systematic approach to Internet memes and virality. Punctum. International Journal of Semiotics, 1(1), 43-66. 10.18680 / hss.2015.0004

Moya-Sánchez, M. \& Herrera-Damas, S. (2015). Cómo puede contribuir Twitter a una comunicación política más avanzada. Arbor, 191. Disponible en bit.ly/2Onskzd

Müller-González, J. F. (2019). (coord.). La sorpresa Vox. Deusto: Grupo Planeta.

Pablo Iglesias decreta "alerta antifascista" y llama a la movilización contra los "postfranquistas" de Vox (2018, diciembre 12). Disponible en bit.ly/3qiSDEa

Pinto-da Fonseca, F. \& Pineda-Nebot, C. (2020). Las expresiones de la derecha en Brasil y en España: conservadurismo, neoliberalismo y fascismo. OXÍMORA Revista Internacional de Ética y Política, (16), 63-84. 10.1344/oxi.2020.i16.29252

Propp, V. (1987). Morfología del cuento, seguida de transformaciones del cuento maravilloso. Madrid: Editorial Fundamentos. 
Talens, J., Romera, J., Tordera, A. \& Hernández, V. (1978). Elementos para una semiótica del texto artístico. Poesía, narrativa, teatro, cine. Madrid: Cátedra.

Valdez Zepeda, A. (20 de diciembre de 2013). ¿Cómo Salir Exitoso de una Campaña Negativa? MPR Group. Disponible en bit. ly/30ly52Z

Vidales, C. (2019). Semiótica, cultura y comunicación. Las bases teóricas de algunas confusiones conceptuales entre la semiótica y los estudios de comunicación. SIEP. Disponible en bit.ly/2OsEjvf

Vox (2018). Cien medidas para la España viva. [programa electoral]. Disponible en bit.ly/3kOWuHC

Warschauer, M., \& Grimes, D. (2007). Audience, authorship, and artifact: The emergent semiotics of Web 2.0. Annual Review of Applied Linguistics, 27, 1-23. https://doi.org/10.1017/S0267190508070013 